Revista de Negócios_ISSN 1980.4431_vol. 19, n. 1, p. 94_117, 2014_DOI:10.7867/1980431.2014v19n1p94_117

\title{
A inovatividade em indústria de alimentos: Estudo com médias e grandes empresas do Sul do Brasil
}

The innovativeness in the food industry: A study of medium and large businesses in Southern Brazil

Cristina Dai Prá Martens

UNINOVE Universidade Nove de Julho - Brasil cristinadpmartens@gmail.com

Henrique Mello Rodrigues de Freitas UFRGS Universidade Federal do Rio Grande do Sul - Brasil hf@ea.ufrgs.br

Gustavo Menegaz Lajus Centro Universitário Univates - Brasil gugalajus@hotmail.com

Eloni José Salvi

Centro Universitário Univates - Brasil esalvi@univates.br

Mauro Luiz Martens

USP Universidade de São Paulo - Brasil mauro.martens@hotmail.com

Recebido em 15 de maio de 2012. Alterado em 8 de julho de 2013. Aprovado em 20 de agosto de 2013.

Editor Responsável: Edson Roberto Scharf, Dr.

Processo de avaliação por double blind review

\section{Resumo}

Este artigo trata da inovatividade sob a ótica da orientação empreendedora. Tem como objetivo apresentar os resultados de um estudo exploratório e qualitativo que buscou caracterizar a inovatividade em indústrias de alimentos. É feita uma revisão conceitual sobre orientação empreendedora e inovatividade, apresentando base conceitual para o estudo. A coleta de dados foi por meio de entrevistas semiestruturadas com dirigentes de nove indústrias de médio e grande porte da região central do Rio Grande do Sul. A análise dos resultados apresenta uma caracterização da inovatividade nas indústrias, que é evidenciada de forma diferente nas indústrias pesquisadas. A inovação em produtos e serviços destaca-se em quatro indústrias, ao passo que a inovação em processos é prioridade em oito das nove indústrias. Há investimentos constantes em inovação, com setor de $\mathrm{P} \& \mathrm{D}$ estabelecido em quatro indústrias e participação ativa do fornecedor nas inovações de duas. Há pessoas dedicadas a atividades inovativas em cinco indústrias e nas demais há envolvimento parcial. A criatividade tem importância destaque, muito embora faltem procedimentos sistematizados para seu desenvol- 
vimento. A diferenciação ocorre especialmente em processos, onde é possível ter atividades inovativas de difícil imitação pela concorrência.

Palavras-chave: Inovatividade. Comportamento inovador. Orientação empreendedora. Empreendedorismo. Indústrias de alimentos.

\begin{abstract}
This article is about innovativeness in the context of entrepreneurial orientation. The aim is to present the results of an exploratory and qualitative research that sought to characterize innovativeness in food industries. A conceptual review on entrepreneurial orientation and innovativeness is presented as a base for the study. Data collection was carried out through semi-structured interviews with professionals of nine medium and large food industries from the central region of Rio Grande do Sul state. The analysis concludes with an over-view about innovative behavior, which is evidenced differently in industries surveyed. Innovation in products and services is featured in four industries, while process innovation is a priority in eight of the nine industries. There is constant investment in innovation, for a department of $P \& D$ in four industries and active participation of the supplier in innovations of the both industries. There are people dedicated to innovative activities in five industries and people involved in the other part. Creativity is especially important, although lacks systematic procedures for its development. The differentiation is especially in cases where it is possible to have innovative activities of difficult for competitors to duplicate.
\end{abstract}

Keywords: Innovativeness. Innovative behavior. Entrepreneurial orientation. Entrepreneurship. Food industry.

\section{Introdução}

A inovatividade tem posição de destaque no contexto de empreendedorismo em virtude de ser um meio pelo qual as organizações buscam diferenciar-se dos seus concorrentes. Segundo Lumpkin e Dess (1996), ela retrata a tendência de uma organização a engajar e apoiar novas ideias, novidades, experimentos e processos criativos que possam resultar em novos produtos, serviços ou processos.

Em uma abordagem mais ampla, a inovatividade é considerada uma dimensão da orientação empreendedora, construto que retrata o empreendedorismo no nível organizacional, refletido no gerenciamento empreendedor. $\mathrm{O}$ conceito de orientação empreendedora emerge da literatura do gerenciamento estratégico e refere-se à postura estratégica empreendedora de uma organização (MILLER; FRIESEN, 1982; MILLER, 1983; COVIN; SLEVIN, 1989; MILLER, 2011), representada nos comportamentos de inovatividade, assunção de riscos, proatividade, autonomia e agressividade competitiva (LUMPKIN; DESS, 1996).

Este estudo tem como pano de fundo o empreendedorismo no nível organizacional (MARTENS et al., 2013) e como foco a inovatividade em organizações, adotando como linha teórica o conceito de inovatividade sob a ótica da orientação empreendedora. $\mathrm{O}$ contexto de desenvolvimento do estudo foi a indústria de alimentos, setor considerado um dos pilares da economia pela sua representatividade e essencialidade (GOUVEIA, 2006).

A indústria brasileira de alimentos é responsável por quase $15 \%$ do faturamento do setor industrial e por empregar mais de um milhão de pessoas (GOUVEIA, 2006). Embora sua relevância, a autora lembra que essa indústria carece de uma trajetória mais consistente na área de inovação. Na mesma linha, a Pesquisa de Inovação Tecnológica PINTEC 2008 aponta que a indústria de produtos alimentícios é considerada uma atividade de baixa intensidade tecnológica. Nesse sentido, uma das justificativas para realização deste estudo está no fato de a indústria de alimentos ser um dos protagonistas do desenvolvimento brasileiro em função de participação financeira e empregabilidade, além deste setor industrial merecer cuidados em temas como inovação e tecnologia.

A orientação empreendedora, onde se destaca a inovatividade, está associada tanto com o desempenho da organização, como com a economia do país. A literatura sugere que quanto mais inovativa a empresa, melhor seu desempenho tanto em competitividade quanto em resultados econômicos (DESS; LUMPKIN, 2005; 
Cristina Dai Prá Martens

Gustavo Menegaz Lajus

Mauro Luiz Martens

MOHAMAD, 2011; FINKLE, 2012; HIT et al., 2012). Por isto, justifica-se um estudo que procure compreender como as empresas tratam e implementam a inovação, para que, a partir deste conhecimento, possam adequar suas estratégias na busca dos resultados esperados.

Este estudo buscou melhor compreender a inovatividade de um grupo de indústrias de alimentos que são a base da economia de uma região do Estado do Rio Grande do Sul. A partir dos conceitos de inovatividade sob a ótica da orientação empreendedora, a pergunta que norteou a realização deste estudo é: como se caracteriza a inovatividade em indústrias de alimentos? Assim, o objetivo deste artigo é fazer uma caracterização a respeito da inovatividade em indústrias de alimentos de médio e grande porte, localizadas no sul do Brasil, a partir da opinião de seus dirigentes.

$\mathrm{Na}$ sequência desta introdução, o texto encontra-se estruturado da seguinte forma: na seção 2 é feita uma breve retomada conceitual sobre orientação empreendedora, remetendo ao conceito de inovação no contexto de empreendedorismo organizacional; na seção 3 aborda-se a inovatividade, bem como a base conceitual que norteou a realização do estudo; na seção 4 discorre-se sobre o método de pesquisa utilizado; na seção 5 são apresentados os resultados obtidos; por fim, na seção 6 são feitas as considerações finais.

\section{O empreendedorismo no nível organizacional}

A orientação empreendedora retrata o empreendedorismo no nível organizacional. Ela emerge da integração dos conceitos de estratégia e empreendedorismo, e tem sido amplamente adotada na literatura de empreendedorismo e em sua relação com a estratégia (BASSO; FAYOLE; BOUCHARD, 2009; WALES; MONSEN; MCKELVIE, 2011). A
Henrique Mello Rodrigues de Freitas

Eloni José Salvi

orientação empreendedora emerge de uma perspectiva de escolha estratégica que afirma que oportunidades de negócios podem ser empreendidas com sucesso, de forma intencional (LUMPKIN; DESS, 1996). Assim, ela envolve as intenções e ações de atores chave em um processo dinâmico, gerador, visando à criação de novos negócios. A orientação empreendedora pode ser considerada como um processo ou modo pelo qual novas iniciativas empreendedoras são desenvolvidas (MILLER, 2011).

A orientação empreendedora e o gerenciamento empreendedor são comceitos análogos utilizados para caracterizar uma organização empreendedora. De acordo com Stevenson e Jarillo (1990), o gerenciamento empreendedor reflete os processos organizacionais, métodos $\mathrm{e}$ estilo que uma organização utiliza para atuar de forma empreendedora. Para Lumpkin e Dess (1996), a orientação empreendedora refere-se aos métodos, práticas e estilo de gestão e de tomada de decisão usados para agir de forma empreendedora. Ambos os conceitos têm em sua essência a atuação empreendedora da organização.

Alguns estudos têm revelado que a orientação empreendedora pode influenciar positivamente o desempenho de uma organização (MILLER, 1983; ZAHRA; COVIN, 1995; FERNANDES; SANTOS, 2008). Wiklund, Patzelt e Shepherd (2009) apontam que ela contribui para o crescimento da organização. Zahra e Covin (1995), afirmam que organizações que atuam de forma empreendedora apresentam efeitos positivos no desempenho financeiro. No entanto, enfatizam que os resultados, num primeiro momento, tendem a serem moderados, obtendo um crescimento ao longo dos anos. Assim, a orientação empreendedora pode favorecer o desempenho financeiro no longo prazo.

Segundo Lumpkin, Cogliser e Schneider (2009), uma empresa com forte orientação empreendedora mantém-se 
sempre informada sobre novas tecnologias e tendências do mercado, e com isso mais facilmente identifica oportunidade. Além de contribuir para a identificação de novas oportunidades, a orientação empreendedora ajuda a manter os decisores focados nas mudanças da indústria e nos movimentos e expectativas dos clientes, o que, em dado momento, poderá favorecer a abertura de um novo empreendimento.

Estudos

clássicos que

desenvolveram o conceito de orientação empreendedora apontavam sua caracterização por meio da inovatividade, da assunção de riscos e da proatividade (MILLER; FRIESEN. 1982; MILLER, 1983; COVIN; SLEVIN, 1989). Na sequência, esse construto foi ampliado por meio da agregação das dimensões autonomia e agressividade competitiva, sendo representado por cinco dimensões (LUMPKIN; DESS, 1996 e 2001; LUMPKIN; COGLISER; SCHNEIDER, 2009; GUPTA; PANDIT, 2012). Essas duas abordagens tem sido adotadas na literatura. Ambas são válidas e distintas, requerendo diferentes medidas para seu estudo (COVIN; WALES, 2012).

Em termos conceituais, a inovatividade é retratada em organizações que se empenham no apoio a novas ideias, novos processos criativos que venham a resultar em novos produtos. Já a assunção de riscos remete às organizações que agem de forma ousada por meio de seus dirigentes, empenhando-se em projetos de risco, muitas vezes com resultados incertos. A proatividade é retratada no comportamento de antecipação e pró-ação da organização, de modo especial na busca por novas oportunidades de mercado. A dimensão autonomia retrata organizações que incentivam a ação independente realizada por indivíduos ou grupo de colaboradores. E por fim, a agressividade competitiva reflete um intenso esforço de uma organização para superar seus rivais, bastante relacionada com a reação a ameaças do mercado.

$O$ fato de essas cinco dimensões caracterizarem uma orientação empreendedora não significa que todas elas devam necessariamente estar presentes em negócios bem sucedidos, que podem acontecer com apenas algumas dessas dimensões, configurando diferentes combinações (LUMPKIN; DESS, 1996; COVIN; LUMPKIN, 2011). Segundo esses autores, o quanto cada uma dessas dimensões é útil para predizer a natureza e o sucesso de um empreendimento pode ser contingente a fatores externos, como o ambiente de negócios, por exemplo, ou a fatores internos, como estrutura organizacional, ou ainda, a características dos fundadores ou líderes da organização. Estudo recente de Vora, Vora e Polley (2012) com médias empresas americanas apresenta evidências a esse respeito.

O Quadro 1, consolidado a partir da literatura, apresenta as dimensões da orientação empreendedora e seus elementos conceituais centrais. 
Mauro Luiz Martens

Quadro 1: Dimensões e elementos centrais da Orientação Empreendedora

\begin{tabular}{|c|c|}
\hline $\begin{array}{c}\begin{array}{c}\text { Dimensões da orientação } \\
\text { empreendedora }\end{array} \\
\end{array}$ & $\begin{array}{l}\text { Elementos centrais das dimensões da orientação } \\
\text { empreendedora }\end{array}$ \\
\hline \multirow{6}{*}{ Inovatividade } & Inovação em Produtos e serviços \\
\hline & Inovação em Processos \\
\hline & Recursos financeiros investidos em inovação \\
\hline & Pessoas envolvidas com atividades de inovação \\
\hline & Criatividade \\
\hline & Diferenciação \\
\hline \multirow{4}{*}{ Assunção de riscos } & Risco geral \\
\hline & Assunção de risco na decisão \\
\hline & Assunção de risco financeiro \\
\hline & Assunção de risco em negócio \\
\hline \multirow{4}{*}{ Proatividade } & Monitoramento do ambiente \\
\hline & Atitude de antecipação \\
\hline & Participação e resolução de problemas \\
\hline & Flexibilidade tecnológica \\
\hline \multirow{4}{*}{ Autonomia } & Equipes e líderes autônomos \\
\hline & Centralização/descentralização \\
\hline & Intraempreendedorismo \\
\hline & Ação independente \\
\hline \multirow{4}{*}{ Agressividade competitiva } & Reação à concorrência \\
\hline & Competição financeira \\
\hline & Competição em negócios \\
\hline & Marketing \\
\hline
\end{tabular}

Fonte: Elaborado pelos autores, com base nos estudos de Miller e Friesen (1978, 1982), Miller (1983), Covin e Slevin (1989), Venkatraman (1989), Chen e Hambrick (1995), Lumpkin e Dess (1996, 2001), Lee e Peterson (2000), Dess e Lumpkin (2005), Stambaugh, Yu e Dubinsky (2011), Freitas et al. (2012).

A inovatividade tem se destacado como uma das dimensões mais típicas no desenvolvimento de práticas empreendedoras (MARTENS et al., 2011; FREITAS et al., 2012; PLAMBECK, 2012), evidenciando a importância da inovação na prática administrativa e, em alguns casos, a sua necessidade (DOUGHERTY, 2004) em função de características do mercado. Estudos apontam que a postura estratégica inovativa está relacionada ao bom desempenho (WIKLUND, 1999) e tem o potencial de gerar vantagem competitiva e promover maior fonte de crescimento para a organização (DESS; LUMPKIN, 2005).

Madhoushi et al. (2011) lembram que literaturas clássicas têm considerado a inovação como um indicador do empreendedorismo e da orientação empreendedora. Em estudo comparativo com empreendedores brasileiros e portugueses, Silva, Gomes e Correia
(2009) identificaram expressiva importância atribuída à inovação. Por outro lado, também existem estudos que apontam barreiras à inovação (LUNA; MOREIRA; GONÇALVEZ, 2008; IBGE, 2010). Assim, a relevância da inovação motiva o aprofundamento do estudo da inovatividade, tema abordado na próxima seção.

\section{A inovatividade sob a ótica da orientação empreendedora}

Os primeiros estudos a abordar a inovação no processo empreendedor foram de Schumpeter, ao tratar da "destruição criadora", onde o empreendedor destrói a ordem econômica existente com a introdução de algo novo (SCHUMPETER, 1982). Para o autor, a inovação é a realização de novas combinações, que englobam: a introdução de um novo bem ou de uma nova qualidade do bem; 
introdução de um novo método de produção; abertura de um novo mercado; conquista de uma nova fonte de oferta de matéria-prima ou de bens semimanufaturados; estabelecimento de uma nova organização de qualquer indústria.

A inovatividade representa a tendência de uma organização a inovar, e pode ser verificada a partir do desenvolvimento de atividades que propiciem a inovação na organização. Segundo Lumpkin e Dess (1996), a inovatividade remete ao desenvolvimento de atividades que possam resultar em novos produtos, serviços e processos. Ela também orienta ações competitivas (STAMBAUGH; YU; DUBINSKY, 2011) e contribui para o desempenho organizacional (KREIZER et al., 2013; CLAUSEN; KORNELIUSSEN; MADSEN, 2013).

Segundo relatório da Pesquisa de Inovação Tecnológica - PINTEC de 2008 (IBGE, 2010), as atividades que as empresas desenvolvem para inovar podem ser de Pesquisa e Desenvolvimento (P\&D) ou outras atividades não relacionadas à $\mathrm{P} \& \mathrm{D}$, que envolvam, por exemplo, aquisição de bens, serviços e conhecimentos externos.

Frishmmar e Hörte (2007) apontam que uma organização que deseja investir consideravelmente no desenvolvimento de novos produtos, terá que se afastar de práticas existentes, e se empenhar em apoiar novas ideias, assim como facilitar os processos criativos. A criatividade no ambiente de trabalho tem destaque no contexto de inovação (FARIA; ALENCAR, 1996; PAROLIN; ALBUQUERQUE, 2010). Aspectos como a autonomia para tentar novas abordagens, o desenvolvimento de projetos colaborativos visando inovação, o direcionamento para impulsionar ou desenvolver tecnologias em parceria com outras instituições, a alta relevância da inovação na estratégia organizacional são alguns dos fatores facilitadores da inovação (PAROLIN et al., 2013). Faria e Alencar (1996) salientam que os gestores interessados em obter um bom desempenho no desenvolvimento de novos produtos, devem orientar sua empresa para o mercado e ao mesmo tempo, esclarecer o objetivo aos subordinados, melhorar a relação entre os departamentos e alterar o sistema de recompensa da empresa. Esses aspectos também remetem à importância da liderança ativa na propensão a inovar (RYAN; TIPU, 2013).

Alguns autores propõem que $\mathrm{o}$ nível de inovatividade de uma organização pode ser determinado a partir de recursos financeiros demandados para atividades de inovação e P\&D; colaboradores destinados a atividades de inovação; frequência no lançamento de novos produtos ou serviços, assim como a frequência na mudança em linhas de produtos e serviços (MILLER; FRIESEN, 1982; COVIN; SLEVIN, 1989). Stock, Six e Zacharias (2012) afirmam que as organizações têm investido consideravelmente em programas para aumentar sua inovatividade, especialmente por meio de uma cultura corporativa orientada à inovação, no intuito de envolver os colaboradores nesse processo. De acordo com os autores, uma cultura orientada à inovação afeta positivamente o desempenho nos negócios por aumentar a inovatividade em produtos.

Para Moreno e Casillas (2008), o grau de inovatividade de uma organização está relacionado ao nível de orientação empreendedora que ela possui, consequentemente influenciando a estratégia que a organização irá utilizar. Por sua vez, Wiklund (1999) aponta que uma postura estratégica inovativa colabora para que a organização identifique oportunidades com mais frequência, e consequentemente mova-se primeiro que seus concorrentes, moldando o ambiente de atuação.

Qualquer forma de inovação envolve uma série de esforços (DESS; LUMPKIN, 2005): a inovatividade tecnológica, por exemplo, envolve primeiramente esforço de pesquisa e de engenharia, focado no desenvolvimento de novos produtos e processos; a 
Mauro Luiz Martens

inovatividade em produto e mercado inclui pesquisa de mercado, design de produto, e inovação em publicidade e promoção; a inovatividade administrativa refere-se a novidades em sistemas gerenciais, técnicas de controle e estrutura organizacional.

Em geral, dois tipos de inovação são mais comumente abordados na literatura: a inovação incremental e a inovação radical. As inovações incrementais são normalmente menores, representadas por adaptações e melhorias, que podem vir de invenções ou proposições dos colaboradores mais ligados ao processo produtivo; já as inovações radicais são resultantes de pesquisa deliberada e muitas vezes conduzem a mudanças substanciais (FREEMAN; PEREZ, 1988).

Independente do tipo de inovação ou do método de classifica-la, a inovação é um importante componente da orientação empreendedora, uma vez que reflete um meio pelo qual as organizações perseguem novas oportunidades. Por outro lado, ela também envolve maior risco, uma vez que os investimentos em inovação podem não ter o retorno esperado. Entretanto, para gerentes estratégicos de organizações empreendedoras, o desenvolvimento bem sucedido e a adoção de novas inovações podem gerar vantagem competitiva $\mathrm{e}$ prover maior fonte de crescimento para a organização (DESS; LUMPKIN, 2005).

O Quadro 2, adaptado de Martens e Freitas (2008), apresenta um conjunto de elementos que caracterizam a inovatividade, elaborado a partir de estudos que tratam desse conceito no contexto de orientação empreendedora, de modo especial Covin e Slevin (1989), Dess e Lumpkin (2005), Lumpkin e Dess (1996) e Miller e Friesen (1982).

\section{Quadro 2: Conjunto de elementos que caracterizam a Inovatividade}

Elementos que caracterizam a Inovatividade em organizações

Lançamento de novos produtos/serviços, novas linhas de produtos/serviços, mudanças frequentes em produtos/serviços e em linhas de produtos/serviços.

Inovação em processos administrativos, inovação tecnológica e em mercado.

Recursos financeiros investidos em inovação, ênfase e investimentos contínuos em $P \& D$, foco em novas tecnologias e em melhoria contínua, liderança tecnológica e inovação.

Recursos humanos comprometidos com atividades de inovação, apoio ao desenvolvimento de novas ideias, novidades, experimentos e processos criativos.

Iniciativas inovativas de difícil imitação por parte dos competidores.

Fonte: Adaptado de Martens e Freitas (2008).

\section{Métodos e técnicas de pesquisa}

O presente estudo é considerado de caráter exploratório e qualitativo (SELLTIZ et al., 1967), tendo buscado a compreensão de determinado fenômeno, no caso a inovatividade em organizações. A unidade de análise foram as indústrias de alimentos de médio e grande porte (segundo $\mathrm{o}$ número de funcionários ${ }^{1}$ ) localizadas na região central do Estado do

\footnotetext{
${ }^{1}$ Adotou-se a classificação do SEBRAE, segundo o número de funcionários, onde médias empresas são as que possuem entre 100 e 499 funcionários e grandes empresas são as que possuem 500 ou mais funcionários (SEBRAE-SP, 2012).
}

Rio Grande do Sul. Considerada um dos principais pólos de produção de alimentos do Estado (CONTO, 2007), a região do Vale do Taquari possui um leque diversificado de indústrias alimentícias destacando-se as dos segmentos de doces (balas e pirulitos), derivados de carne (aves e embutidos) e laticínios. Esses segmentos encontram-se entre os principais na indústria alimentícia brasileira (ABIA, 2009).

Embora grande parte das indústrias do setor de alimentos sejam microempresas e empresas de pequeno porte, neste estudo optou-se por buscar indústrias de médio e grande porte, 
considerando que, via de regra, tratam-se de empresas já consolidadas, atuando há diversos anos no mercado e, possívelmente, têm a gestão mais estruturada. Além disso, são as que geram a maior parte dos postos de trabalho do setor na região foco do estudo (CONTO, 2007).

Para a definição da amostra do estudo, foi consultada a base de dados do SEBRAE-RS, tendo sido identificadas 19 indústrias de alimentos de médio e grande porte na região, sendo 12 médias e 7 grandes. Das 19, cinco indústrias foram excluídas considerando que faziam parte de um mesmo grupo empresarial de outras constantes na lista, o que poderia levar a resultado repetitivo. Assim, restaram 14 indústrias que foram foco do estudo. Para a coleta de dados foi contatado o principal dirigente de cada indústria. Após o contato inicial, executivos de nove indústrias dispuseram-se a participar do estudo. Nas demais, foram apresentadas justificavas como venda recente da empresa, dificuldade financeira e indisponibilidade do executivo.

As nove indústrias participantes do estudo situam-se em cinco diferentes municípios da região, cinco delas são de médio porte e quadro de grande porte. São representantes dos segmentos de laticínios (3 indústrias), balas (2), erva-mate (1), aditivos e condimentos alimentares (1), laticínios/derivados de carne (1) e bebidas (1). A média de colaboradores das empresas é de 280 nas de médio porte e de 900 nas de grande porte. Sete das nove indústrias exportam, sendo que duas têm o mercado externo como principal mercado de atuação. As demais têm atuação no mercado nacional, a exceção de uma que comercializa seus produtos somente no estado do Rio Grande do Sul.

A coleta de dados foi realizada por meio de entrevistas semiestruturadas com o principal dirigente das indústrias, entre os meses de setembro e outubro de 2009. Em sete indústrias as entrevistas foram realizadas de forma presencial, gravadas e posteriormente transcritas para a análise dos resultados. Dois dirigentes não tiveram disponibilidade para fazer entrevista face a face, mas se dispuseram a responder ao roteiro de entrevista a distância, tendo retornado suas respostas por e-mail.

O Quadro 3 apresenta a base do roteiro de entrevistas utilizado no estudo. Os elementos da inovatividade foram categorizados visando facilitar sua identificação no contexto organizacional.

Quadro 3: Categorias e elementos que embasaram o roteiro de entrevistas.

\begin{tabular}{|l|l|}
\hline \multicolumn{1}{|c|}{ Categorias } & \multicolumn{1}{c|}{ Elementos da Inovatividade } \\
\hline Produtos e serviços & $\begin{array}{l}\text { Novos produtos/serviços. } \\
\text { Novas linhas de produtos/serviços. } \\
\text { Mudanças em produtos/serviços e em linhas de produtos/serviços. } \\
\text { Frequência de mudança em produtos/serviços e em linhas de produtos/serviços. }\end{array}$ \\
\hline \multirow{3}{*}{ Processos } & $\begin{array}{l}\text { Inovação administrativa. } \\
\text { Inovação tecnológica. } \\
\text { Inovação em mercado. }\end{array}$ \\
\hline Recursos financeiros & $\begin{array}{l}\text { Recursos financeiros investidos em inovação. } \\
\text { Assegura investimentos em P\&D mesmo em períodos de dificuldade econômica. } \\
\text { Investe em novas tecnologias, P\&D e melhoria contínua. }\end{array}$ \\
\hline Eessoas & Ênfase em P\&D, liderança tecnológica e inovação. \\
\hline Criatividade & Recursos humanos comprometidos com atividades de inovação. \\
\hline Diferenciação & Engajar e apoiar novas ideias, novidades, experimentos e processos criativos. \\
\hline
\end{tabular}

Fonte: Elaborado pelos autores, adaptado de Martens e Freitas (2008).

A análise dos dados coletados teve início com a leitura das transcrições e escuta dos áudios, visando sua revisão. As duas entrevistas respondidas por e-mail foram lidas de forma atenta visando identificar eventual necessidade de 


\section{Mauro Luiz Martens}

informação complementar (o que não foi necessário). Após isso, os textos transcritos foram organizados segundo as categorias e elementos da inovatividade e cotejados com a literatura. Uma revisão dos elementos e das categorias foi realizada pelos pesquisadores (KRIPPENDORFF, 1980), por meio de leitura e releitura, em momentos distintos, com intervalo de tempo, permitindo sua confirmação.

Assim, os dados foram analisados de forma qualitativa, fazendo uso de técnicas de análise de conteúdo, buscando compreender os dados obtidos, identificando neles os elementos da inovatividade e categorizando-os de acordo com a base conceitual adotada no estudo. Seguiram-se algumas etapas do modelo para análise de entrevistas não estruturadas proposto por Mattos (2006), sendo elas: a recuperação do momento da entrevista, a análise do significado pragmático da conversação, a montagem da consolidação das falas e a análise de conjuntos. Seguiuse a orientação de Tesch (apud GODOY, 2006), que sugere que a análise deve incluir uma atividade reflexiva que resulta num conjunto de notas que guiam $o$ processo, ajudando o pesquisador a moverse dos dados empíricos para o nível conceitual, visando formar categorias, estabelecer fronteiras, encontrar evidências. A seguir são apresentados os resultados do estudo sobre a inovatividade.

\section{Caracterizando a inovatividade em indústrias de alimentos}

Esta seção caracteriza a inovatividade nas indústrias de alimentos que participaram do estudo, a partir das entrevistas realizadas com os nove executivos. Ela está organizada segundo as categorias da inovatividade: Produtos e serviços, Processos, Recursos financeiros, Pessoas, Criatividade e Diferenciação. Ao longo da seção são apresentados trechos das entrevistas visando melhor ilustrar a realidade relatada pelos executivos.

\subsection{Produtos e serviços}

O lançamento de produtos/serviços e as mudanças em produtos/serviços apresentam diferentes realidades nas indústrias pesquisadas. Em algumas indústrias é comum o lançamento de novos produtos com grande frequência, podendo chegar a diversos lançamentos mensalmente. Dois executivos deram evidências a respeito em suas falas.

Todo mês tem produto novo [...] quando a gente fala de refrigerados, todo mês tem um produto novo, diferente. [...] na área de iogurte teve a entrada, no último mês, de vários produtos. $\mathrm{O}$ iogurte muda constantemente, sabe, muda todo mês, até é difícil mensurar porque todo mês muda um monte; no mínimo 5 produtos mudaram. (Executivo 1)

[...] é uma característica do nosso setor [doces] estar sempre apresentando novidade. Então todos os meses, praticamente, a gente tem lançamento de novo produto. [...] Até o momento, fizemos 31 lançamentos neste ano [período de 10 meses]. Até o final do ano temos a previsão de lançar mais uns quatro ou cinco. (Executivo 7)

A realidade apontada pelo executivo da indústrias de doces é corroborada por outro entrevistado do mesmo segmento, que aponta que a média de lançamento de novos produtos fica em torno de 15 produtos anualmente, em cada uma das 3 unidades da empresa. Isso retrata a necessidade de inovação (ZAHRA; COVIN, 1995; LUMPKIN; DESS, 1996; DOUGHERTY, 2004) para manter a posição no mercado. Essas mudanças em produtos, e mesmo o lançamentos de novos produtos, muitas vezes ocorrem por meio de inovações incrementais (FREEMAN; PERES, 1988), realizadas pela alteração em uma fórmula, em uma embalagem, no formato do produto, no sabor, o que acaba mudando o 
posicionamento do produto numa mesma categoria ou resultando em um novo produto.

Outro executivo relatou que em função de características do mercado, a empresa redirecionou sua comercialização para o mercado interno a partir de 2008, quando anteriormente seu maior foco era a exportação. Isso fez com que fosse intensificada a inovação. Passaram a realizar campanhas inovadoras de marketing e novos produtos foram lançados, conforme ilustrado em trecho de sua entrevista.

[...] na área de suínos nós lançamos, recentemente, 20 novos produtos que estão entrando no mercado. Então foi uma inovação bastante significativa: importamos máquinas, lançamos produtos com porções menores, temperados [...] buscando um novo olhar sobre a carne suína nova apresentação, nova forma de vender o produto [...] nós vamos encerrar um ano que foram lançados muitos produtos. (Executivo 3)

Por outro lado, três dos nove entrevistados deixaram claro que não há uma frequência definida para o lançamento de produtos e que isso ocorre de acordo com a necessidade do mercado. Nesses casos, o lançamento de novos produtos tem sido pouco frequente, se comparado com os casos anteriormente relatados. Uma das indústrias aponta que faz, em média, o lançamento de um novo produto a cada dois anos. Cabe salientar que se trata de uma empresa fornecedora de matéria prima para a indústria de alimentos, onde as inovações estão diretamente vinculadas à demanda do cliente.

Outro executivo, representando as indústrias que possuem inovações em produtos com menor frequência, fala sobre a observação do mercado para lançar produtos, atitude importante para a identificação de oportunidades que possam resultar em novas linhas de produtos e/ou serviços ou novos produtos e/ou serviços
(DESS; LUMPKIN, 2005). "A ordem é, analisar o mercado, dentro da nossa capacidade produtiva, e lançar produtos. No mínimo três a quatro novos produtos por ano é uma tendência de lançamento", afirma o Executivo 2.

Um dado curioso apontado por um dos executivos entrevistados retrata a dificuldade de lançar novos produtos em virtude de barreiras impostas pela área comercial. Segundo o entrevistado, a indústrias possui uma meta de lançamento de 10 novos produtos em seu planejamento estratégico, mas na prática isso não ocorre. Há uma equipe de pesquisa e desenvolvimento dedicada, mas a falta de um mecanismo comercial estruturado de marketing para lançamento de produtos impede que isso de fato ocorra, conforme retratado em sua fala.

O comercial acha que lançar muitos produtos é ruim para eles porque eles querem trabalhar produto por produto. Na verdade, eles querem que sejam lançados produtos na velocidade em que eles comportam, e nós aqui, como criação, a gente tem uma autonomia maior de ficar pensando coisas novas, de ficar acompanhando o que está acontecendo no mercado e até de estar propondo algumas inovações, no entanto acaba colidindo com eles lá - uma represa, chamada comercial. (Executivo 5)

Esse caso destoa do que a literatura costuma apresentar como barreiras à inovação. Para Luna, Moreira e Gonçalves (2008), normalmente as barreiras à inovação estão associadas a riscos econômicos excessivos, elevados custos de inovação, e escassez de fontes de financiamento. $\mathrm{O}$ relatório da PINTEC 2008 (IBGE, 2010) aponta como inibidores da inovação fatores de natureza econômica, problemas internos à indústrias relacionados à rigidez organizacional, deficiências técnicas, problemas de falta de informações sobre tecnologia e sobre os 


\section{Mauro Luiz Martens}

mercados, escassas possibilidades de cooperação com outras empresas/instituições e dificuldade para se adequar a padrões, normas e regulamentações. No caso relatado, percebe-se uma carência no setor comercial ao não fornecer o suporte necessário para que os novos produtos cheguem ao mercado.

Outro executivo relata a dificuldade de lançar novos produtos, em função do tamanho da empresa diante da forte concorrência multinacional em seu setor [bebidas]. "Pra gente conseguir o registro do produto, para registrar uma marca nova, leva muito tempo e o mercado é muito dinâmico. Nossos grandes concorrentes [...] cada um deles têm um portfólio de marcas em estoque", afirma o entrevistado. Embora isso, a indústria está frequentemente buscando melhorias nos produtos já existentes: "A gente está sempre procurando modificar os produtos, melhorar a sua composição, no entanto muitas vezes isso não é percebido pelo consumidor" (Executivo 4). Esse relato está alinhado com os resultados de um estudo com empresas de refrigerantes locais que mostra que é preciso investir constantemente em inovação e seguir as tendências apontadas pelos grandes competidores do mercado, com destaque às inovações em processos visando redução de custos e melhoria da qualidade (OLIVEIRA; UENO, 2011).

A partir do relato dos executivos acerca da inovatividade em produtos $\mathbf{e}$ serviços, foram identificadas três situações distintas que retratam esse comportamento nas nove indústrias foco do estudo: algumas inovam constantemente, com alta frequência de lançamento de novos produtos/serviços e alterações em produtos/serviços (4 empresas); outras fazem lançamentos ou mudança nos produtos/serviços de acordo com a necessidade do mercado, não havendo uma frequência estabelecida (3); e ainda um terceiro grupo tem uma baixa frequência de lançamento e mudança em produtos/serviços (2).

\subsection{Processos}

Gonçalves (2000, p. 14), afirma que "os processos são a fonte das competências 'específicas da empresa' que fazem a diferença em termos de concorrência". Segundo o autor, os processos criam a eficiência de hoje e do futuro. Citando Kanter (1997), ele lembra que a inovação nos processos pode melhorar as capacitações organizacionais.

As inovações em processos administrativos, nas tecnologias e na atuação no mercado parecem ser preocupação constante nas indústrias pesquisadas. Alguns entrevistados relataram que a inovação em processos é realizada por meio de implementação de tecnologias de ponta, de softwares avançados, de adequação a programas de qualidade, aspectos que retratam as inovações administrativas (LUMPKIN; DESS, 2005). Também são destacadas aquisições de novas máquinas, no intuito de inovar no processo tecnológico, e mesmo de novas unidades. As indústrias buscam, com essas inovações, uma maior competitividade no mercado, o fortalecimento da marca, a melhoria contínua e a evolução constante nos processos internos. Dois trechos de entrevistas ilustram essa realidade.

Quando a gente fala de gestão de inovação, agora mesmo, nesse mês, nós estamos comprando cinco ferramentas novas de trabalho para a engenharia, para cuidar de novos projetos [...]. Estamos comprando um tipo diferenciado de autocad, msproject e um outro sistema para poder projetar as tubulações, as linhas da fábrica - o que agiliza muito. (Executivo 1)

Procuramos sempre a melhoria contínua através de ferramentas informatizadas e automação de equipamentos e de processos [...]. Vivemos em constante mudança 
de máquinas e equipamento, sempre na busca pela melhor qualidade e produtividade. (Executivo 9)

Um dos executivos relatou que sua indústria tem investido muito em tecnologias de ponta, usando como exemplo uma unidade em fase de construção que terá tecnologias de última geração, que hoje, no Brasil, apenas uma multinacional do setor possui. Outro entrevistado, além de mencionar que muitas inovações ocorrem em nível de fábrica, enfatizou que atualmente as inovações estão mais voltadas para a construção da marca por meio de inovações na forma da divulgação, a exemplo de expositores diferenciados nos pontos de venda. Ele afirma que a empresa, em todos os aspectos, está buscando melhoria contínua e evolução constante nos processos internos, com o intuito de transformar essa ideia em uma cultura dentro da empresa. Já um terceiro executivo relata que as inovações nos processos internos estão baseadas no Programa Gaúcho de Qualidade, conforme trecho de sua entrevista.

\begin{abstract}
Isso é o que mais ocorre [inovações em processos], pois quando entramos no Programa Gaúcho da Qualidade passamos a trabalhar muito as ferramentas do programa gaúcho junto com nossos planejamentos planejamento estratégico de curto, médio e longo prazo. Através dos planejamentos se trabalha muito a avaliação de desempenho que é acompanhado desde a alta administração até os gerentes de área [...] e muita coisa a gente redireciona em reuniões mensais isso em área administrativa, de gestão. E em termos de indústria, estamos constantemente de olho nos fluxos de produção, layout da indústria. (Executivo 3)
\end{abstract}

Dentre os nove executivos, apenas um relatou que a indústria não tem perfil inovador nos processos administrativos.
Ele afirma que a empresa está passando por um crescendo muito rápido, e tem necessidade de adequação de sua estrutura: “a empresa está dobrando o seu faturamento em pouquíssimo tempo, o que significa também dobrar fábrica, pessoas, processos. Tem muita coisa acontecendo junto, então gera um crescimento desorganizado", afirma o Executivo 5. Em sua fala, percebe-se a necessidade de antes dar suporte para esse crescimento, para então pensar em processos mais organizados e inovações nesse contexto.

A partir do relato dos executivos no que se refere à inovatividade em processos, verificou-se que apenas uma das nove indústrias não possui o perfil inovador em processos, sendo que as demais têm a inovação em processos como algo presente no dia-a-dia.

\subsection{Recursos financeiros}

Com respeito aos investimentos em atividades de inovação, identificou-se que apenas quatro das nove indústrias possuem um setor dedicado para a pesquisa e desenvolvimento (P\&D), corroborando uma realidade apontada por Gouveia (2006) de indústrias de alimentos que não possuem um departamento de P\&D. Entre as indústrias que possuem, em duas delas o setor de P\&D situa-se na unidade industrial onde atua o executivo que participou da pesquisa, enquanto, nas outras duas, o setor localiza-se na matriz do grupo.

As parcerias com universidades, laboratórios e fornecedores também são destacadas. Uma indústria realiza parceria com universidades e laboratórios para o desenvolvimento de atividades de inovação. Também há casos onde a pesquisa e desenvolvimento é realizada pelos fornecedores, a exemplo de fornecedores de aromas e de matériasprimas formuladas para a industrialização dos alimentos, retratando a cooperação para inovação (IBGE, 2010). Um entrevistado retrata esse tipo de cooperação. 
Cristina Dai Prá Martens

Gustavo Menegaz Lajus

Mauro Luiz Martens

Hoje o fornecedor já vem com as novidades do mundo inteiro [...]. Claro que ele te traz os componentes e a mistura é feita aqui dentro; mas ele é quem desenvolve. Hoje ele desenvolve as novidades, eu não preciso mais ter uma equipe aqui para isso, mas eu tenho uma equipe que pega: ah, eu vou pegar um produto de um fornecedor, outro do outro e outro do outro e vou fazer a composição da nossa empresa. (Executivo 4)

Fica claro, na entrevista, que a indústria investe pouco em pesquisa e desenvolvimento, contudo tem boa parceria com seu fornecedor para essa finalidade. Corroborado essa realidade, outro entrevistado também mencionou que muitas vezes são os fornecedores que trazem as inovações, mas embora isso a indústria também possui um laboratório, que está dividido em duas partes: uma parte que atende mais diretamente a produção e outra mais voltada para a análise e desenvolvimento de produtos.

Embora esses investimentos, na maior parte das indústrias não há um valor definido destinado à pesquisa e desenvolvimento. Trechos de entrevistas exemplificam a realidade sobre investimentos em inovação em algumas organizações.

Costumamos investir em P\&D em parceria com universidades, com laboratórios [...] eles acabam sendo parceiros nossos no desenvolvimento de pesquisas e de produtos. Há pesquisas onde os próprios laboratórios realizam junto com as universidades [...]. No final do ano passado nós abrimos uma gerência que cuida exclusivamente da área de qualidade e de pesquisa. [...] Fizemos investimentos fortes em laboratórios. [...] $\mathrm{Na}$ área da indústria têm pessoas exclusivamente pensando em lançamentos e elaboração de novos produtos [...]. Não tenho
Henrique Mello Rodrigues de Freitas

Eloni José Salvi

um valor definido de quanto é investido, mas é um valor significativo. (Executivo 3)

Nós temos um centro de pesquisa e desenvolvimento dentro da empresa. Nós temos uma estrutura hoje com um projeto dos três laboratórios juntos, umas quinze pessoas trabalhando. Investimos mais ou menos $1 \%$ do faturamento. (Executivo 6)

A pesquisa e desenvolvimento é um setor corporativo que atende a todas as unidades com os testes sendo feitos em cada unidade. Por exemplo: tem um produto que tem que ser inovado, aí vem aqui e faz o teste aqui. As pessoas que desenvolvem essas atividades são daqui e de fora, junto com fornecedores; às vezes precisa da engenharia de processos. (Executivo 1)

Um executivo manifestou que a indústria, por ser nova no mercado e estar crescendo, ainda não tem uma verba específica destinada para o $\mathrm{P} \& \mathrm{D}$, nem possui um setor formalizado para tal. No entanto, faz algum investimento em inovação. Outras indústrias exemplificaram esses investimentos por meio de alterações em linhas de produtos, lançamento de produtos inovadores, treinamentos das pessoas, investimentos em laboratórios, entre outros, com o intuito de criar um diferencial em relação à concorrência.

Ao serem indagados quanto ao investimento em $\mathrm{P} \& \mathrm{D}$ em épocas de crise, a maioria dos executivos respondeu que os investimentos são assegurados, a exemplo desses relatos.

O leite tem bastante oscilações de épocas devido à estiagem. [...] Em razão dessas oscilações, a gente optou por investir sempre, claro não no mesmo nível de época "gorda". Mas como são períodos temporários não pode esperar para investir, para quando ficar bom começar a investir. Aí tu vai ter o 
resultado quando já está no período ruim de novo. (Executivo 2)

Nós pensamos que em cima da necessidade, a gente faz as mudanças e as inovações. [...] as pessoas estão liberadas para pensarem e fazerem as inovações que acham que devam ser feitas; muitas vezes são inovações que envolvem recursos, investimentos, mas sempre tem um planejamento para que possa se fazer ao longo do tempo. (Executivo 3)

Em geral, no que se refere a recursos financeiros para inovação, identificou-se que oito das nove indústrias costumam investir constantemente em pesquisa e desenvolvimento, mesmo em épocas de crise. A exceção se dá para uma indústrias que investe muito pouco em inovação tendo em vista que o fornecedor supre a sua necessidade em termos de pesquisa e desenvolvimento de produtos. Todavia, entre as indústrias pesquisadas, o valor destinado para atividades de inovação não é identificado contabilmente, $\mathrm{e}$ apenas um executivo pesquisado quantificou esse investimento em cerca de $1 \%$ do faturamento.

Dados da PINTEC (IBGE, 2010) apontam que a indústria investiu, em 2008, $2,5 \%$ do seu faturamento em atividades inovativas, sobressaindo-se os investimentos em aquisição de máquinas e equipamentos, que foram responsáveis pela metade do recurso investido. Já o setor de fabricação de produtos alimentícios é apontado com um percentual de investimento de $2,09 \%$ sobre o faturamento, e o de bebidas de 2,25\%, segundo os dados da mesma pesquisa. Ambos percentuais são superiores ao $1 \%$ apontado pelo executivo neste estudo.

\subsection{Pessoas}

No que se refere à existência de pessoas comprometidas com atividades de inovação nas indústrias estudadas, os executivos retrataram realidades bem diferentes. Na maioria das indústrias há pessoas envolvidas com atividades de inovação. No entanto, em alguns casos existem colaboradores dedicados exclusivamente a essas atividades, enquanto em outros não há algo formalizado, um setor ou uma equipe específica.

Um dos entrevistados manifestou a existência de um 'comitê de produtos' em sua indústrias, que realiza reuniões mensais para cuidar exclusivamente de inovações e mudanças em produtos. Outro executivo, além de relatar que a indústria possui uma equipe voltada para a análise e desenvolvimento de produtos, mencionou que há uma pessoa dedicada a realizar viagens pela Europa, a visitar fornecedores, a fazer treinamentos, enfim, a envolver-se em atividades diversas no intuito de acompanhar as inovações do setor pelo mundo.

Um dado interessante apontado por outro entrevistado é a participação do cliente no desenvolvimento de novos produtos, posto que se trata de empresa de suprimentos para outras indústrias. Trechos de sua entrevista retratam tal situação.

\footnotetext{
Temos pessoas voltadas para essas atividades de pesquisa e desenvolvimento e nós temos apoio também dos próprios clientes que vêm aqui dentro ajudar, falar da necessidade dos produtos e dar algumas ideias de como poderiam ser feitos os produtos. Como um caso recente que foi uma necessidade do cliente. E daí ela é desenvolvida aqui, às vezes a gente compra projetos, às vezes é desenvolvido aqui. (Executivo 6)
}

Um entrevistado relatou que a indústria onde atua possui pessoas dedicadas à atividades de inovações em diferentes áreas: " $\mathrm{Na}$ área de comércio e marketing há pessoas envolvidas nos lançamentos de novos produtos; na indústria há pessoas exclusivamente pensando em novos produtos: temperos, 
Cristina Dai Prá Martens

Gustavo Menegaz Lajus

Mauro Luiz Martens

cortes, sabores", ilustra o Executivo 3.

Em uma das indústrias, as pessoas dedicadas para atividades de inovação estão situadas na matriz, mas dão suporte às demais unidades. Há também uma empresa que não possui pessoas dedicadas a atividades de inovação: "Hoje o fornecedor desenvolve as novidades, eu não preciso mais ter uma equipe para isso; ele deixa amostras de seus produtos porque para ele é negócio, eu não compro. O meu investimento é somente em tempo de trabalho dos funcionários, e o tempo eles administram bem dentro do horário deles" (Executivo 4).

No que se refere a pessoas para inovação, em geral há colaboradores envolvidos com atividades de inovação na maioria das indústrias, mas nem sempre dedicados com exclusividade para isso. As indústrias que possuem profissionais com dedicação para atividades de inovação, via de regra, são as que têm um setor de P\&D. Foram evidenciados casos de investimento considerável em equipe e qualificação para tal, mas também há um caso onde não há investimento em pessoas para atividades de inovação.

\subsection{Criatividade}

A literatura destaca a importância da criatividade e da experimentação na geração de novos produtos, novos serviços, novos processos (DESS; LUMPKIN, 2005; PAROLIN; ALBUQUERQUE, 2010; PAROLIN et al., 2013). Nas indústrias pesquisadas parece não haver uma metodologia ou processo formalizado para estímulo à criatividade. Existem algumas iniciativas pontuais voltadas para programa de sugestões, como exemplificado nos trechos a seguir.

Tem um programa de sugestões. As sugestões podem ser das mais variadas: sugestão de produto, como também uma melhoria industrial, uma melhoria de processo, qualquer coisa que gere um ganho para a empresa, seja em
Henrique Mello Rodrigues de Freitas

Eloni José Salvi

inovação, seja em qualidade, seja em custo [...] Todas as ideias que acontecem são premiadas. (Executivo 5)

[...] as sugestões são analisadas por um Comitê e as melhores são premiadas. São analisadas pelo Comitê que estuda a viabilidade e o retorno. (Executivo 8)

Outro exemplo são as reuniões setoriais, no intuito de contribuir para que os funcionários proponham ideias. Segundo um dos executivos, é também objetivo dessas iniciativas criar uma cultura de observação e proposição de melhorias. Outro entrevistado faz certa crítica a programas de ideias, com base em experiências anteriores. Ele também relata a existência de uma postura bastante aberta à participação em sua indústria, visando estimular a colaboração das pessoas. Isso fica claro em um trecho de sua entrevista.

Em outra empresa onde trabalhei a gente tinha um projeto interno para que os funcionários propusessem ideias, elas eram avaliadas e as melhores ideias recebiam prêmios. No entanto, chegou num ponto que parecia que as pessoas só davam ideias e recebiam prêmios. Baseado nessa experiência, aqui a gente tem uma abertura muito grande, as nossas portas, mesmo as dos gerentes, estão sempre abertas para as pessoas irem colaborando, e se tem muitos processos de discussão de melhoria. (Executivo 7)

Outra iniciativa pontual pode ser destacada em trecho da fala do Executivo 3: "há um dia em que grupos, ou até mesmo as pessoas mais simples, apresentam estudos de como reduzir perdas ou custos em todos os setores da empresa, desde o setor de abate até o setor administrativo. Aí sim é estimulado, é dado um prêmio para a equipe que conseguir montar o melhor projeto; isso traz resultados fantásticos". Mas em geral, 
a participação dos colaboradores com proposição de novas ideias é feita de maneira informal nas indústrias pesquisadas, e é incentivada por meio da participação nos projetos, na participação nos lucros e na possibilidade de crescimento. Trechos de entrevistas relatam a respeito.

Não tem um incentivo no papel, estruturado. O que a gente busca é dar oportunidades para as pessoas dentro da empresa. Então hoje uma pessoa que está na empresa e desenvolve um trabalho bom, diferenciado, quando surgir uma oportunidade para o setor acima sempre se olhará para o funcionário que já está dentro da empresa. Claro, em alguns setores buscamos fora também, mas tem muita oportunidade interna. (Executivo 2)

Eu acho que é o próprio espaço delas dentro da empresa, não tem assim uma coisa definida no plano de cargos/salários, mas existe a satisfação pessoal e a exposição, o profissional que consegue isso vai ao natural aparecer no meio dos demais; está impregnado isso dentro da empresa, todos têm a sua oportunidade e a empresa trabalha com participação nos resultados, então a equipe pega junto - se alguém tem uma ideia boa sai todo mundo atrás da ideia para tentar buscar resultados; é uma cultura e com isso se criou também uma cultura de trabalho em equipe [...]. (Executivo 3 )

No que se refere à criatividade para a inovação, depreende-se das entrevistas com os executivos que as indústrias estimulam seus funcionários a serem criativos e proporem melhorias. No entanto, nem todas possuem um método ou sistema formalizado para essa finalidade. Em algumas organizações, o incentivo é o próprio espaço dos funcionários dentro da empresa, na tentativa de fazer com que a participação seja algo cultural. De certa forma isso condiz com estudo de Faria e
Alencar (1996), que destacam, entre os principais fatores que contribuem para o estímulo à criatividade no ambiente de trabalho, o suporte organizacional, a estrutura organizacional e o suporte da chefia.

\subsection{Diferenciação}

Com respeito à diferenciação, grande parte dos entrevistados manifestou que é difícil desenvolver alguma iniciativa inovativa em produtos que seja de difícil imitação pela concorrência. Segundo eles, a diferenciação da empresa normalmente está voltada para a gestão, para as estratégias comerciais, para a maneira de atender o cliente e de explorar os mercados, para o poder de investimento e para a marca. Dois executivos apontaram o investimento e a marca como fatores essenciais para a diferenciação no mercado de hoje, conforme trechos de suas entrevistas.

O nosso segmento hoje está muito globalizado, não tem mais um produto que seja exclusivo, todo mundo pode fazer, desde que faça um investimento. [...] Hoje, toda tecnologia é conhecida por todo mundo; depende de investimento e de ter marca para ter uma diferenciação. A diferenciação está voltada para duas coisas: investimento e marca. (Executivo 1)

[...] hoje a coisa mais difícil é o mercado, porque equipamento tu compra, eles te vendem a tecnologia. Agora, é difícil comprar mercado no curto prazo. Equipamento tá aqui, no máximo em um ano tá aqui, tá produzindo; agora conquistar mercado em um ano já é mais difícil, por isso essa valorização tão grande e cada vez maior nas marcas. Ter uma marca hoje vale mais que a empresa; em princípio, é ela que vai te fazer ter faturamento, (Executivo 7)

Nas entrevistas são identificados exemplos de diferenciação por meio da 
Mauro Luiz Martens

inovação em processos. Um executivo destaca o cuidado da indústria com a produção de alimentos, levando em consideração a qualidade nesse processo. Outro aponta a disponibilidade de produtos para atender o cliente de imediato: "A diferenciação da nossa empresa, hoje, é ter um estoque para nosso cliente, chega a ter caminhões parados no pátio para esperar a necessidade do cliente. A diferenciação está nessa parte de processos, que é mais difícil de copiar. Produto é fácil de copiar" (Executivo 6). Também é evidenciada a diferenciação por meio do sistema de gestão, conforme ilustrado em trechos dessa entrevista.

Nós começamos um projeto de gestão na empresa que desde a nossa visão, nossa missão, nossos princípios e o sistema com que a gente administra a empresa envolve, de certa forma, todo mundo. [...] Então essa maneira de pensar, de montar planejamento estratégico e a maneira com que a gente divide as tarefas, onde o presidente não é o dono da razão, muito pelo contrário tem uma equipe pensando junto. [...] Buscamos ideias na Europa adaptando às realidades locais e principalmente em cima das qualidades das pessoas (perfil). (Executivo 3)

Outro executivo aponta a dificuldade de se diferenciar no seu setor de atuação (leite e derivados), pois o processo é praticamente o mesmo em todas as indústrias do setor. No entanto, ele destaca como diferencial uma linha específica de produtos, em razão da região onde é produzido [outra unidade industrial da empresa] ser tradicional para o produto, o que agrega valor e faz grande diferença no mercado.

Divergindo da maioria dos entrevistados, um executivo apontou uma iniciativa inovativa em produtos como diferencial perante a concorrência. Embora isso, ele considera que qualquer indústria que queira fazer o mesmo produto pode, mas leva um tempo mínimo de oito meses entre encomendar o projeto e lançar o produto. Com isso, por conta do pioneirismo, a empresa ganha tempo e parcela de mercado até que a concorrência imite (WIKLUND, 1999).

De forma resumida, o que se conclui das entrevistas sobre a diferenciação no contexto de inovatividade, é que normalmente a diferenciação não está em produto, mas sim em serviços, em processos, em marca, em outros aspetos mais peculiares de cada empresa, que são mais difíceis de serem imitados pela concorrência. Apenas um dos entrevistados apontou o produto, salientando a vantagem de ser pioneiro e a necessidade de capitalizar enquanto a concorrência não lança produto similar.

\section{Considerações finais: a inovatividade nas indústrias de alimentos pesquisadas}

Ao final deste estudo sobre a inovatividade em indústrias de alimentos, cabe ressaltar alguns aspectos sobre esse comportamento nas organizações pesquisadas. Em geral, as nove indústrias pesquisadas apresentam características de inovatividade. A partir de uma análise individual de cada categoria da inovatividade (produtos e serviços, processos, recursos financeiros, pessoas, criatividade e diferenciação), constatou-se que os elementos relativos à inovatividade manifestam-se de forma mais intensa em algumas indústrias do que em outras. Essa diferença parece ocorrer em função de motivos diversos: segmento de atuação, mercado, concorrência, tempo no mercado, força da marca, disponibilidade de recursos para investir em atividades voltadas para a inovação, perfil do dirigente, entre outros. Cabe salientar que tais motivos são aqui apresentados a partir da percepção dos autores, considerando as entrevistas realizadas com os executivos, mas não foram foco de análise mais profunda. 
A análise dos resultados apresentada ao longo da seção 5 teve um caráter subjetivo e qualitativo, procu apresentar uma caracterização sobre o comportamento inovador das indústrias pesquisadas, sempre buscando trechos de depoimentos dos executivos para ilustrar a realidade ou chamar atenção a aspectos pontuais. Tendo como ponto de partida para a coleta e análise dos dados a base conceitual apresentada no Quadro 3 deste artigo, pode-se afirmar que as categorias e elementos da inovatividade foram explicitados nas entrevistas dos executivos, permitindo verificar na prática organizacional o que é apontado pela literatura.

Os resultados da pesquisa possibilitam fazer uma classificação preliminar sobre o comportamento inovador nas nove empresas, considerando as categorias da inovatividade, conforme apresentado no Quadro 4, a seguir. Essa classificação não pretende mensurar a inovatividade, mas visa dar uma sinalização sobre o comportamento inovador das nove indústrias, a partir da percepção dos pesquisadores, tendo como base as entrevistas realizadas e a revisão bibliográfica.

Quadro 4: Inovatividade nas indústrias pesquisadas: uma classificação preliminar

\begin{tabular}{|c|c|c|c|c|c|c|c|c|c|c|c|}
\hline \multirow[t]{2}{*}{$\begin{array}{l}\text { Categorias da } \\
\text { inovatividade }\end{array}$} & \multirow[t]{2}{*}{$\begin{array}{c}\text { Classificação preliminar sobre a } \\
\text { inovatividade nas indústrias }\end{array}$} & \multicolumn{9}{|c|}{$\begin{array}{c}\text { Indústrias cujos executivos foram } \\
\text { entrevistados }\end{array}$} & \multirow[t]{2}{*}{ Total } \\
\hline & & 1 & 2 & 3 & 4 & 5 & 6 & 7 & 8 & 9 & \\
\hline \multirow{3}{*}{$\begin{array}{l}\text { Produtos e } \\
\text { Serviços }\end{array}$} & Inovam constantemente & $\mathrm{x}$ & & $\mathrm{x}$ & & & & $\mathrm{x}$ & $\mathrm{x}$ & & 4 \\
\hline & Inovam conforme a necessidade do mercado & & $\mathrm{x}$ & & & & $\mathrm{x}$ & & & $\mathrm{x}$ & 3 \\
\hline & Inovam com pouca frequência & & & & $\mathrm{x}$ & $\mathrm{x}$ & & & & & 2 \\
\hline \multirow{2}{*}{ Processos } & Inovam constantemente em processos & $\mathrm{x}$ & $\mathrm{x}$ & $\mathrm{x}$ & $\mathrm{x}$ & & $\mathrm{x}$ & $\mathrm{x}$ & $\mathrm{x}$ & $\mathrm{x}$ & 8 \\
\hline & Inovam com pouca frequência em processos & & & & & $\mathrm{x}$ & & & & & 1 \\
\hline \multirow{3}{*}{$\begin{array}{l}\text { Recursos } \\
\text { financeiros }\end{array}$} & Possuem setor de P\&D & $\mathrm{x}$ & $\mathrm{x}$ & $\mathrm{x}$ & & & $\mathrm{x}$ & & & & 4 \\
\hline & P\&D é realizada por fornecedores & & & & $\mathrm{x}$ & & & $\mathrm{x}$ & & & 2 \\
\hline & $\begin{array}{l}\text { Assegura investimentos em P\&D, mesmo em } \\
\text { épocas de dificuldades econômicas }\end{array}$ & $\mathrm{X}$ & $\mathrm{X}$ & $\mathrm{x}$ & & $\mathrm{x}$ & $\mathrm{x}$ & $\mathrm{x}$ & $\mathrm{X}$ & $\mathrm{x}$ & 8 \\
\hline \multirow{2}{*}{ Pessoas } & $\begin{array}{l}\text { Colaboradores dedicados exclusivamente } \\
\text { com atividades de inovação }\end{array}$ & $\mathrm{X}$ & $\mathrm{x}$ & $\mathrm{x}$ & & & $\mathrm{x}$ & $\mathrm{x}$ & & & 5 \\
\hline & $\begin{array}{l}\text { Colaboradores envolvidos com atividades de } \\
\text { inovação }\end{array}$ & & & & $\mathrm{x}$ & $\mathrm{x}$ & & & $\mathrm{x}$ & $\mathrm{x}$ & 4 \\
\hline \multirow{2}{*}{ Criatividade } & $\begin{array}{l}\text { Procedimento formalizado para que os } \\
\text { colaboradores proponham melhorias }\end{array}$ & & & & $\mathrm{x}$ & $\mathrm{x}$ & $\mathrm{x}$ & & $\mathrm{X}$ & $\mathrm{x}$ & 5 \\
\hline & $\begin{array}{l}\text { Incentivo a criatividade e proposição de } \\
\text { melhorias faz parte da cultura da empresa }\end{array}$ & $\mathrm{x}$ & $\mathrm{x}$ & $\mathrm{x}$ & & & & $\mathrm{x}$ & & & 4 \\
\hline \multirow[t]{2}{*}{ Diferenciação } & $\begin{array}{l}\text { Busca diferenciação em processos (gestão, } \\
\text { estratégias comerciais, marca, atuação em } \\
\text { mercados e clientes, etc.) }\end{array}$ & $\mathrm{x}$ & $\mathrm{x}$ & $\mathrm{x}$ & $\mathrm{x}$ & $\mathrm{x}$ & $\mathrm{x}$ & $\mathrm{x}$ & $\mathrm{x}$ & $\mathrm{x}$ & 9 \\
\hline & $\begin{array}{l}\text { Busca diferenciação pela inovação em } \\
\text { produtos }\end{array}$ & $\mathrm{X}$ & & $\mathrm{x}$ & & $\mathrm{x}$ & & $\mathrm{x}$ & $\mathrm{X}$ & & 5 \\
\hline
\end{tabular}

Fonte: elaborado pelos autores.

No que se refere a produtos e serviços, o Quadro 4 demonstra que quatro indústrias apresentam um comportamento de inovar constantemente, ao passo que três inovam conforme a necessidade do mercado e duas inovam com pouca frequência. Não se pode afirmar que exista um comportamento mais adequado, ou que as indústrias que inovam pouco devam inovar mais, pois dependendo do segmento ou mercado, a inovação em produtos pode não ser uma necessidade da organização. Por exemplo, o setor de bebidas tem uma característica de seguir produtos lançados 
Mauro Luiz Martens

por marcas multinacionais, o que lhe permite andar num ritmo mais lento de inovação. Já o setor de doces [balas e pirulitos] enfrenta uma realidade completamente diferente, onde é necessário estar inovando constantemente, sob pena de não se manter competitivo no mercado. Vale salientar que as inovações em produtos identificadas no estudo são, em sua maioria, inovações incrementais, corroborando o estudo de Gouveia (2006) que afirma que as inovações na indústria de alimentos são majoritariamente incrementais.

Já a inovação em processos é retratada como uma preocupação constante para oito das nove indústrias pesquisadas, visto que apenas uma delas não inova constantemente em processos. Como diversos executivos deixaram claro em suas entrevistas, a prestação de serviços tem sido a forma de buscar a diferenciação, corroborando o que Gonçalves (2000) afirma sobre os processos como diferencial perante a concorrência. Em se tratando de um setor que trabalha com commodities, isso fica ainda mais evidente.

Com relação a recursos financeiros para inovação, vale destacar que os entrevistados afirmam que as indústrias investem continuamente, mesmo em tempos de dificuldades financeiras. Isso espelha uma realidade onde a inovação tem sido importante para essas indústrias, seja em produtos, seja em processos, cada indústrias em seu contexto. Outros pontos a considerar são a existência do setor de pesquisa e desenvolvimento em quatro organizações, e a participação ativa do fornecedor nas inovações em produto de duas indústrias onde a inovação é fortemente baseada em componentes prontos adquiridos. Com menor evidência, também aparece a parceria entre indústrias e instituições de pesquisa e laboratórios para o desenvolvimento de inovações.

Cabe considerar que entre as indústrias pesquisadas, apenas uma quantificou o investimento em atividades inovativas, num percentual de $1 \%$ sobre o faturamento, valor que fica abaixo da média da indústria de produtos alimentícios $(2,09 \%)$ e da indústria de bebidas (2,25\%) (IBGE, 2010). Considerando que a referida empresa possui setor de P\&D e pessoal dedicado para atividades inovativas, pode-se especular que seja uma das indústrias com razoável recurso investido, dentre as nove que participaram do estudo. Se isso é fato, sinalizaria um baixo investimento em atividades inovativas pelas indústrias cujos executivos foram entrevistados.

No que se refere a pessoas para inovação, foi constatado que em todas as organizações há pessoas envolvidas com atividades de inovação, e de modo especial em cinco delas, há pessoas dedicadas exclusivamente para essa finalidade. Entre essas cinco indústrias estão as quatro que possuem um setor de $\mathrm{P} \& \mathrm{D}$, três delas inovam constantemente em produtos e duas de acordo com a necessidade do mercado. Este último aspecto chama atenção, pois embora as indústrias inovem conforme necessidade do mercado, possuem pessoas permanentemente dedicadas para atividades de inovação.

Sobre a criatividade, importante conceito no contexto de inovação, é evidente a importância atribuída pelos entrevistados a este aspecto. As nove indústrias focam ou estimulam a criatividade, seja por meio de procedimento formalizado ou já como algo cultural. Contudo, embora alguns executivos tenham demonstrado haver um ambiente com liberdade para que as pessoas participem com ideias e sugestões de melhorias, salienta-se a importância de existirem procedimentos formalizados que estimulem essa participação.

Por fim, quanto à diferenciação, os nove entrevistados apontaram que ela ocorre especialmente em processos, onde é possível ter atividades inovativas de difícil imitação pela concorrência, fato que corrobora a importância atribuída por eles 
à inovação em processos. No que se refere à diferenciação em produtos, cinco entrevistados apontaram que ela também é foco, contudo, com o avanço tecnológico, dificilmente se cria algo que a concorrência não esteja fazendo ou que não possa imitar rapidamente. $\mathrm{O}$ avanço tecnológico e a rápida disseminação da informação contribuem para que o pioneirismo não perdure por muito tempo, cabendo às empresas capitalizarem enquanto estão à frente da concorrência a partir de uma iniciativa inovativa. De toda forma, se o foco é diferenciar-se pela inovação, é fundamental estar constantemente em busca de novidades.

Os resultados deste estudo permitem apontar contribuições acadêmicas e gerenciais. Em termos de contribuição acadêmica, a revisão conceitual sobre orientação empreendedora e inovatividade resume um referencial pertinente para a realização de estudos nessas temáticas, consolidado nos Quadros 1 e 2, com a apresentação de dimensões e elementos a respeito. A aplicação da teoria na prática organizacional é outro aspecto a considerar, uma vez que permite confirmar a aplicação da base conceitual sobre a inovatividade para a verificação desse comportamento nas organizações. Outra contribuição acadêmica que pode ser apontada refere-se a uma barreira à inovação que parece não ter sido sinalizada anteriormente pela literatura, e que foi relatada por um dos executivos entrevistados ao apontar que a área de vendas da empresa é o "pé no freio" para inovações em produtos, retratando uma barreira interna à inovação.

Em termos de contribuições gerenciais, este estudo permite agregar conhecimento e experiência aos profissionais que atuam na indústria de alimentos, bem como contribui para uma reflexão sobre a prática organizacional no que se refere à inovatividade. Tal reflexão pode ser realizada a partir da base conceitual adotada no estudo, dos resultados do estudo (caracterização sobre a inovatividade nas organizações) e dos trechos de depoimentos dos executivos. Uma análise desses aspectos pode dar indicativos para ação aos profissionais que desejarem inovar em suas organizações. Além disso, as práticas gerenciais apresentadas ao longo da seção 5, seja nos trechos das entrevistas, seja na análise, permitem aportar conhecimento sobre a indústria de alimentos e a inovação no setor.

Considerando que a inovatividade está associada ao desempenho em termos de competitividade e de resultados econômicos (DESS; LUMPKIN, 2005; MOHAMAD, 2011; FINKLE, 2012; HIT et al., 2012), este estudo contribui apresentando elementos direcionadores da inovatividade no contexto organizacional, a saber Produtos e serviços, Processos, Recursos financeiros, Pessoas, Criatividade e Diferenciação, que podem auxiliar gestores e empresários nas ações para potencializar a inovatividade. Em última análise, isso pode direcionar esforços na busca por maior competitividade $\mathrm{e}$ resultados econômicos.

Em geral, espera-se que o estudo também contribua com o debate e desenvolvimento da temática do empreendedorismo no nível organizacional e do comportamento inovador em organizações, seja pela teoria de base utilizada, seja pelos resultados empíricos encontrados, permitindo uma melhor compreensão do comportamento inovador nas organizações.

Como limitações deste estudo pode-se citar o fato da coleta de dados ter sido restrita a entrevistas com o principal dirigente das organizações. Um estudo mais aprofundado, com entrevistas com colaboradores e análise de documentos da organização poderia possibilitar uma caracterização mais precisa sobre a inovatividade nas empresas, o que pode também sinalizar uma oportunidade de pesquisa.

Para pesquisas futuras, sugere-se a busca de uma maior amostra de indústrias 
Cristina Dai Prá Martens

Gustavo Menegaz Lajus

Mauro Luiz Martens

de alimentos, de diferentes segmentos, visando apontar características da inovatividade segundo as diferenças setoriais. Outros setores também podem ser foco desse tipo de estudo, bem como outros métodos e abordagens podem ser utilizadas, visando à confirmação de alguns resultados e mesmo sua aplicação a outros contextos e realidades.

\section{Referências}

ABIA. Associação Brasileira das Indústrias de Alimentação, 2009. Disponível em <http://www.abia.org.br>. Acessado em 21 Jul. 2009.

BASSO, O.; FAYOLLE, A.; BOUCHARD, V. L'orientation entrepreneuriale: Histoire de la formation d'un concept. Revue Française de Gestion, n. 195, p. 175-192, 2009.

CHEN, M. J.; HAMBRICK, D. C. Speed, stealth, and selective attack: how small firms differ from large firms in competitive behaviour. The Academy of Management Journal, v. 38, n. 2, p. 453-482, april 1995.

CLAUSEN, T. H.; KORNELIUSSEN, T.; MADSEN, E. L. Modes of innovation, resources and their influence on product innovation: Empirical evidence from R\&D active firms in Norway. Technovation, v.33, n. 6-7, p. 225-233, Jun-Jul 2013.

CONTO, S. M. Análise das inovações no processo produtivo para exportar: um estudo de múltiplos casos de empresas alimentícias de médio porte do Vale do Taquari-RS. Dissertação. 129 f. (Mestrado) - Universidade Federal do Rio Grande do Sul, Escola de Administração, Programa de Pós-Graduação em Administração, Porto Alegre, 2007.

COVIN J. G.; LUMPKIN, G. T. Entrepreneurial Orientation Theory and Research: Reflections on a Needed
Henrique Mello Rodrigues de Freitas

Eloni José Salvi

Construct. Entrepreneurship Theory and Practice. v. 35, n. 5, p. 855-872, 2011.

COVIN, J. G.; SLEVIN, D. P. Strategic management of small firms in hostile and benign environments. Strategic Management Journal, v. 10, n. 1, p. 75-87, 1989.

COVIN, J. G.; WALES, W. J. The Measurement of Entrepreneurial Orientation. Entrepreneurship: Theory \& Practice, v. 36, n. 4, p. 677-702, jul. 2012.

DESS, G. G.; LUMPKIN, G. T. The role of entrepreneurial orientation in stimulating effective corporate entrepreneurship. The Academy of Management Executive, v. 19, n. 1, p. 147-156, Feb. 2005.

DOUGHERTY, D. Organizando para a inovação. In: CLEGG, S. R.; HARDY, C.; NORD, W. R. (Org.). Handbook de estudos organizacionais. São Paulo: Atlas, 2004. v. 3, p. 337-360.

FARIA, M. F. B.; ALENCAR, E. M. L. S. Estímulos e barreiras à criatividade no ambiente de trabalho. Revista de Administração. v. 31, n. 2, Abr.-Jun. 1996

FERNANDES, D. V. H.; SANTOS, C. P. Orientação empreendedora: um estudo sobre as consequências do empreendedorismo nas organizações. Revista de Administração de Empresas - eletrônica, v. 7, n. 1, p. 1-28, 2008.

FINKLE, T. A. Corporate Entrepreneurship and Innovation in Silicon Valley: The Case of Google, Inc. Entrepreneurship Theory and Practice, v. 36, n. 4, p. 863884, July 2012.

FREEMAN, C.; PEREZ, C. Structural crises of adjustment: business cycles and investment behaviour. In: DOSI, G.; FREEMAN, C.; NELSON, R.; SILVERBERG, G.; SOETE, L. (eds.). Technical change and economic theory, London: Pinter Publishers, Londres, 1988. p. 38-66. FREITAS, H.; MARTENS, C. D. P.; BOISSIN, J.-P.; BEHR, A. Elementos para guiar ações visando à orientação empreen- 
dedora em organizações de software. Revista de Administração. v. 47, n. 2, p.163-179, 2012.

FRISHMMAR, J.; HÖRTE, S. A. The role of market orientation and entrepreneurial orientation for new product development performance in manufacturing firms. Technology Analysis \& Strategic Management, v. 19, n. 6, p.765-788, Nov. 2007.

GODOY, A. S. Estudo de caso qualitativo. In: GODOI, C. K.; BANDEIRA-DEMELLO, R.; SILVA, A. B. (org.). Pesquisa qualitativa em estudos organizacionais: paradigmas, estratégias e métodos. São Paulo: Saraiva, 2006. p. 115146.

GONÇALVES, J. E. L. As empresas são grandes coleções de processos. Revista de Administração de Empresas. v. 40, n. 1, p. 6-9, 2000.

GOUVEIA, F. Indústria de alimentos: no caminho da inovação e de novos produtos. Inovação Uniemp, v. 2 n. 5, Campinas, Nov./Dec. 2006.

GUPTA, R.; PANDIT, A. Strategic Entrepreneurial Orientation: Development of a Multi-Dimensional Construct Based on Literature Review. South Asian Journal of Management, v. 19, n. 4, p. 89-110, out. 2012.

HITT, M. A.; IRELAND, R. D.; SIRMON, D. G.; TRAHMS, C. A. Strategic Entrepreneurship: Creating Value for Individuals, Organizations, and Society (January 28, 2012). Mays Business School, Research Paper No. 2012-19. Available at: <http://ssrn.com/abstract=1994491>.

IBGE. Instituto Brasileiro de Geografia e Estatística. Pesquisa de inovação tecnológica - PINTEC 2008 / IBGE, Coordenação de Indústria. Rio de Janeiro: IBGE, 2010.

KREISER, P. M.; MARINO, L. D.; KURATKO, D. F.; WEAVER, K. M. Disaggregating Entrepreneurial Orientation: The Non-Linear Impact of Innovativeness, Proactiveness and Risk-Taking on SME Performance. Small Business Economics, v. 40, n. 2, p. 273-291, 2013.

KRIPPENDORFF, K. Content analysis: an introduction to its methodology. Newbury Park, California: Sage Publications, 1980.

LEE, S. M.; PETERSON, S. J. Culture, Entrepreneurial orientation, and global competitiveness. Journal of World Business, v. 35, n. 4, p. 401-416, 2000.

LUMPKIN，G. T.; COGLISER， C. C.; SCHNEIDER, D. R. Understanding and measuring autonomy: an entrepreneurial orientation perspective. Entrepreneurship Theory \& Practice, p.47-69, Jan. 2009.

LUMPKIN, G. T.; DESS, G. G. Clarifying the entrepreneurial orientation construct and linking it to performance. Academic of Management Review, v. 21, n. 1, p. 135-172, january 1996.

LUMPKIN, G. T.; DESS, G. G. Linking two dimensions of entrepreneurial orientation to firm performance: the moderating role of environment and industry life cycle. Journal of Business Venturing, v. 16, n. 5, p. 429-451, Sep. 2001.

LUNA, F.; MOREIRA, S.; GONÇALVES, A. Financiamento à Inovação. In: DE NEGRI, J. A.; KUBOTA, L. C. Políticas de Incentivo à Inovação Tecnológica no Brasil (Editores). Brasília: IPEA, 2008.

MADHOUSHI, M.; SADATI, A.; DELAVARI, H.; MEHDIVAND, M.; MIHANDOST, R. Entrepreneurial Orientation and Innovation Performance: The Mediating Role of Knowledge Management. Asian Journal of Business Management, v. 3, n. 4, p. 310-316, nov. 2011.

MARTENS, C. D. P.; FREITAS, H. M. R. Orientação Empreendedora nas organizações e a busca de sua facilitação. Gestão.Org, v. 6, p. 90-108, 2008.

MARTENS, C. D. P.; FREITAS, H. M. R.; BOISSIN, J.-P.; BEHR, A. Elementos da 
Cristina Dai Prá Martens

Gustavo Menegaz Lajus

Mauro Luiz Martens

Inovatividade no Setor Software: estudo exploratório em organizações empreendedoras do Rio Grande do Sul. Revista de Administração e Inovação, v. 8, n. 1, p. 248-279, 2011.

MARTENS, C. D. P.; PISCOPO, M. R.; PINHO, M. S.; CARNEIRO, K. D. A. Entrepreneurship in Organizations: A Bibliometric Study Between 2002 and 2012. In: IAMOT. 22nd International Conference on Management of Technology, 2013, Porto Alegre. Anais do IAMOT 2013, 2013. p. 1-17.

MATTOS, P. L. C. L. Análise de entrevistas não estruturadas: da formalização à pragmática da linguagem. In: GODOI, C. K.; BANDEIRA-DE-MELLO, R.; SILVA, A. B. (Ed.). Pesquisa qualitativa em estudos organizacionais: paradigmas, estratégias e métodos. São Paulo: Saraiva, 2006. p.347-374.

MILLER, D. The correlates of entrepreneurship in three types of firms. Management Science, v. 29, n. 7, p. 770791, Jul. 1983.

MILLER, D.; FRIESEN, P. H. Archetypes of strategy formulation. Management Science, v. 24, n. 9, p. 921-933, May 1978.

MILLER, D.; FRIESEN, P. H. Innovation in conservative and entrepreneurial firms: two models of strategic momentum. Strategic Management Journal, v. 3, n. 1, p. 1-26, Jan./Mar. 1982.

MILLER, D. Miller (1983) Revisited: A Reflection on EO Research and some Suggestions for the Future. Entrepreneurship Theory and Practice. v. 35, n. 5, p. 873-894, 2011.

MOHAMAD, O.; RAMAYAH, T.; PUSPOWARSITO, H.; NATALISA, D.; SAERANG, D. P. E. Corporate Entrepreneurship and Firm Performance: The Role of Business Environment as a Moderator. Journal of Management Research, v. 10 n. 3, p. 7, July 2011.
Henrique Mello Rodrigues de Freitas

Eloni José Salvi

MORENO, A. M.; CASILLAS J. C. Entrepreneurial orientation and growth of smes: a causal model. Entrepreneurship Theory \& Practice, p. 507-528, Mar. 2008.

OLIVEIRA, L. H.; UENO, F. E. A guerra das tubaínas: estratégias competitivas das indústrias de refrigerantes populares. Revista da Universidade Vale do Rio Verde, Três Corações, v. 9, n. 2, p. 35-60, Ago./Dez. 2011.

PAROLIN, S. R. H.; ALBUQUERQUE, L. G. Gestão de pessoas para a criatividade em organizações inovativas. Revista Eletrônica de Administração. Edição 67, 16(3), set/dez, 268-297, 2010.

PAROLIN, S. R. H.; VASCONCELLOS, E.; VOLPATO, M.; LAURINDO, A. M. Barriers and Facilitators of Collaborative Management in Technological Innovation Projects. Journal of Technology Management \& Innovation, v. 8, Special Issue ALTEC, p. 151-164, 2013.

PLAMBECK, N. The development of new products: The role of firm context and managerial cognition. Journal of Business Venturing, v. 27, p. 607-621, 2012.

RYAN, J.; TIPU, S. Leadership effects on innovation propensity: A two-factor full range leadership model. Journal of Business Research, v. 66, n.10, p. 2116, 2013.

SCHUMPETER, J. A. Teoria do Desenvolvimento Econômico. São Paulo: Abril Cultural, 1982.

SEBRAE-SP. Estudos e Pesquisas. Micro e Pequenas Empresas em números. Disponível em: <http://www.sebraesp. com.br/TenhoUmaEmpresa/Biblioteca/Out rosConteudos/EstudosEPesquisas/MPEsE mNumeros/Paginas/MPEsEmNumeros.asp $\mathrm{x}>$. Acesso em 01/05/2012.

SELLTIZ, C.; JAHODA, M.; DEUTSCH, M. Métodos de pesquisa nas relações sociais. São Paulo: Herder, 1967.

SILVA, M. A. O. M.; GOMES, L. F. A. 
M.; CORREIA, M. F. Cultura e orientação empreendedora: uma pesquisa comparativa entre empreendedores em incubadoras no Brasil e em Portugal. Revista de Administração Contemporânea. v. 13 , n. 1 , p. 57-71, 2009.

STAMBAUGH, J. S.; YU, A.; DUBINSKY, A. J. Before the Attack: A Typology of Strategies for Competitive Aggressiveness. Journal of Management Policy and Practice, vol. 12, n. 1, p. 4963, 2011.

STEVENSON, H. H.; JARILLO, J. C. A paradigm of entrepreneurship: entrepreneurial management. Strategic Management Journal, v. 11, n. 5, p. 17-27, 1990.

STOCK, R. M.; SIX, B.; ZACHARIAS, N. A. Linking multiple layers of innovationoriented corporate culture, product program innovativeness, and business performance: a contingency approach. Journal of the Academy of Marketing Science, v.41, n.3, p. 283-299, May 2013.

VENKATRAMAN, N. Strategic orientation of business enterprises: the construct, dimensionality and measurement. Management Science, v. 35, n. 8, p. 942-962, august 1989.

VORA, D.; VORA, J.; POLLEY, D. Applying entrepreneurial orientation to a medium sized firm. International Journal of Entrepreneurial Behaviour \& Research, vol. 18, n. 3, p.352-379, 2012.

WALES, W.; MONSEN, E.; MCKELVIE, A. The Organizational Pervasiveness of Entrepreneurial Orientation. Entrepreneurship: Theory \& Practice, v. 35, n. 5, p. 895-923, set. 2011.

WIKLUND, J. The sustainability of the entrepreneurial orientation-performance relationship. Entrepreneurship: Theory \& Practice, v. 24, n. 1, p. 37-48, 1999.

WIKLUND, J. PATZELT, H.; SHEPHERD, D. A. Building an integrative model of small business growth. Small Business Economics, v. 32, p. 351-374, 2009.
ZAHRA, S. A.; COVIN, J. G. Contextual influences on the corporate entrepreneurship - performance relationship: a longitudinal analysis. Journal of Business Venturing, v. 10, n. 1, p. 43-58, Jan. 1995. 